\title{
O Brincar no Ambiente Urbano: Limites e Possibilidades em Ruas e Parquinhos de uma Metrópole
}

\author{
Playing in Urban Environments: Limits and Possibilities in Streets \\ and Playgrounds of a Metropolis
}

\author{
Gabriela Souza Cotrim \& Ilka Dias Bichara* \\ Universidade Federal da Bahia, Salvador, Brasil
}

\begin{abstract}
Resumo
A proposta desse trabalho foi realizar um levantamento das diversas formas de ocupação do espaço urbano externo para brincadeiras em Salvador. Utilizou-se a fotografia de eventos como dados, que foram categorizados em: locais para crianças (geralmente parquinhos) e locais não planejados para crianças (ruas, rotatórias etc.). Foram computados 111 eventos, sendo 91 em parquinhos públicos e 20 em espaços não planejados. Constataram-se diferenças na forma de ocupação desses dois tipos de espaços e no tipo de brincadeira: brincadeira de exercício físico nos aparelhos nos locais para e jogos de regras nas áreas livres nos locais não para. Encontraram-se diferenciações também relacionadas ao papel do adulto (cuidador e brincante) e a presença de meninos e meninas.

Palavras-chave: Espaços urbanos, brincadeiras infantis, parques infantis.
\end{abstract}

\begin{abstract}
The purpose of this study was to conduct a survey on different urban space used for playing in Salvador-Bahia. Pictures of events were used as data collection and were categorized into: 'places for children' (usually playgrounds) and 'places not projected for children' (streets, traffic islands, etc.). In total, 111 events were computed: 91 in public playgrounds and 20 in places not intended for children's playing. Differences were noted in the form of occupation of those two types of spaces and in the kind of playing: physical exercises with equipment in 'places for', and games with rules at open areas in 'places not for'. It was also found differences related to the adult's role (caregiver and active agent) and the presence of boys and girls.

Keywords: Urban space, children's play, playgrounds.
\end{abstract}

Ao andar pelas grandes cidades brasileiras percebem-se modos distintos de ocupação do espaço urbano por crianças: umas brincando em parquinhos, outras tantas morando e lutando pela sobrevivência muitas vezes em situação de alto risco e, mesmo assim, brincando em locais os mais diversos, tenham sido eles planejados ou não para esses usos.

Apesar disso, e de constatar que grande parte das pesquisas sobre infância tem se dedicado às atividades infantis atreladas ao contexto em que elas ocorrem, percebe-se que o contexto urbano, principalmente no que concerne a ocupação dos espaços externos, pouco tem sido abordado pelos trabalhos em psicologia do desenvolvimento. A ênfase da psicologia tem sido dada aos ambientes internos como escolas, creches, clínicas e residências (Meneghini \& Campos-de-Carvalho, 2003; Sager, Sperb, Roazzi, \&

${ }^{*}$ Endereço para correspondência: Ladeira do Acupe, 856, Apto. 704, Acupe de Brotas, Salvador, BA, Brasil 40290 160.E-mail: gcotrim@hotmail.come ilkadb@ufba.br
Martins, 2003). Observa-se, entretanto, que em outras áreas do conhecimento como a educação, sociologia e geografia, o contexto urbano externo tem sido bastante lembrado por diversos pesquisadores ao redor do mundo, como contexto significante para o estudo do comportamento infantil (Ellis, 2004; Karsten, 2003; Rasmussen, 2004). A esse respeito, Colonna e Brás (2011) registram o surgimento de uma área específica de investigação, a geografia da infância, que parte do principio de que as "espacialidades" têm relevância no quotidiano das crianças, e de seus significados sociopolíticos.

A importância dada ao ambiente urbano não parece ser arbitrária, pois é nas cidades que a maioria da população mundial vive, e consequentemente, onde se encontra a maior parte das crianças. Assim, investigar como as crianças se comportam em ambientes externos, públicos e visíveis de uma metrópole pode nos revelar aspectos importantes sobre a infância na contemporaneidade, principalmente aqueles associados à ocupação de espaços, busca de autonomia e sociabilidade, fenômenos estes expressos majoritariamente em brincadeiras. 
Segundo Santos e Bichara (2005) ambientes diferentes proporcionam modos diferentes de brincar o que leva a crer que contexto e brincadeira estão intimamente ligados. Ademais, conhecer as singularidades de cada ambiente bem como seus aspectos culturais não é somente de fundamental relevância na compreensão da brincadeira, mas da própria compreensão do desenvolvimento humano (Kobarg, Kuhnen, \& Vieira, 2008; Lordelo, 2002). Sendo assim, o estudo do ambiente público urbano, como um dos ambientes que faz parte do dia-a-dia das crianças da cidade, possui fundamental importância na compreensão da brincadeira infantil, já que as suas peculiaridades e formas de organização podem afetar sobremaneira os tipos de usos e adaptações que as crianças fazem desses espaços, assim como a forma como se relacionam com outras crianças e adultos.

Sabe-se que muitos fatores influenciam a forma com que os espaços urbanos são organizados socialmente, no entanto, duvidamos de que as crianças não percebam os efeitos dessa organização. Nas últimas décadas, o tempo e o espaço destinados às crianças foram essencialmente modificados em função de graves fenômenos bastante conhecidos, quais sejam: a violência, a presença de estranhos, drogas, atividades ilícitas, tráfego de veículos, entre outros fatores que parecem ser ameaças universais no mundo moderno.

Como efeito desses fenômenos, alguns, tipicamente urbanos, o brincar foi deslocado de fora para dentro. As crianças perderam o espaço externo, o espaço público urbano se tornou menos utilizado e acessível (Karsten \& Vliet, 2006). A tentativa por manter as crianças distantes dos problemas urbanos foi colocá-las dentro de espaços essencialmente segregados da vida social da comunidade, mantendo-as seguras e distantes dos perigos físicos e das más influências (Bartlett, 2002).

A título de exemplo desses locais, temos os parquinhos públicos, que já se tornaram comum nas cidades, quase como presença indispensável nas praças. Segundo Karsten (2003), estes parquinhos nada mais são do que efeito de uma intenção de compensar as restrições diárias que as crianças encontram no ambiente urbano. No entanto, apesar de as crianças terem sido deslocadas a espaços cada vez mais seguros e planejados, elas sempre resistiram a essa tendência, expressando de variadas formas a preferência pela autodeterminação e pela brincadeira espontânea perto de casa e do dia-a-dia da sua família (Bartlett, 2002).

A partir dessa mesma constatação, Rasmussen (2004) propôs a distinção entre "espaços para as crianças" (aqueles planejados pelos adultos para elas) e "espaços das crianças" (aqueles apropriados por elas). O autor constatou, em comparação realizada em espaços diferenciados na Dinamarca, que os espaços das crianças eram ricos, variáveis, sem estrutura preestabelecida, resultado do mundo simbólico e da criatividade infantil. Nessa mesma perspectiva Hart (2002, citado por Rasmussen, 2004) afirma que as crianças preferem os locais que elas encontram por elas mesmas, em vez daqueles oferecidos ou destinados a elas.

Dessa forma, a rua, como espaço livre, emerge como um local rico e relevante para o desenvolvimento infantil, um espaço que possibilita o que os parquinhos tornaram ineficiente, como aborda Matthews (2003) ao dizer que na rua as crianças dedicam tempo ao convívio dos seus pares possibilitando usos diferenciados de ocupação do espaço urbano, com possíveis encontros com crianças de idades diferenciadas, de ambos os gêneros, levando a entender a perspectiva social das relações e das posições. A rua nessa perspectiva é vista como uma passagem não somente em direção aos arredores e ao contato da vizinhança, mas como uma passagem para a fase adulta, pois experienciar a rua, na perspectiva do autor, é a parte central da separação da infância para a vida adulta. A rua permite que a criança desenvolva competências sociais e leve a cabo seu amadurecimento distante de casa e da vizinhança (Christensen \& O’Brien, 2003; Colonna \& Brás, 2011; Mekideche, 2004; Silva, Pontes, da Silva, Magalhães, \& Bichara, 2006).

Porém, em metrópoles como as brasileiras, perigosas e violentas, essa ocupação das ruas não se dá apenas por autonomia e desejo de crescer de forma independente, mas sim por fatores socioculturais diversos, suscitando algumas questões pontuais: são as mesmas crianças que frequentam um e outro lugar? As brincadeiras são as mesmas? Há diferenças entre a organização das brincadeiras nos parquinhos públicos e na rua, ou mesmo canteiros de avenidas, rotatórias entre avenidas ou largos e praças sem equipamentos? Como se organizam as crianças por gênero? Pode-se dizer que o papel do adulto é o mesmo nesses lugares?

Assim, nos propusemos a realizar um levantamento amostral das diversas formas de ocupação do espaço urbano externo para brincadeiras na cidade de Salvador, da relação entre as formas de ocupação e as brincadeiras encontradas, características desses espaços tanto em termos físicos quanto sociais, objetos presentes, participação de adultos e preferências por gênero. Para tal, adaptamos a diferenciação proposta por Rasmussen (2004) fazendo contraponto entre as ocupações dos locais para (planejados para o uso infantil) e locais não para (não planejados para crianças, mas ocupado por elas).

Acredita-se que ao acrescentar à literatura dados de uma cidade brasileira contribui-se com a compreensão do fenômeno em um contexto não tão particular, mas em muito comum aos países em desenvolvimento, em muito negligenciados pelas teorias dominantes sobre o desenvolvimento, que se fundamentam basicamente em estudos com crianças de classe média Européia e Norte Americana (Göncün, Tuermer, Jain, \& Johnson, 1999).

\section{Método}

A pesquisa aqui descrita é parte de um projeto maior sobre espaços urbanos para brincar e que, por se tratar de 
um levantamento amostral, procurou utilizar uma estratégia que permitisse o alcance desse objetivo de forma ampla e com poucos recursos. Para tal, se utilizou a fotografia de eventos como estratégia para a coleta de dados, estratégia essa já bastante utilizada em outras áreas como a antropologia e sociologia e que agora começa a ganhar espaço na psicologia (Flick, 2009).

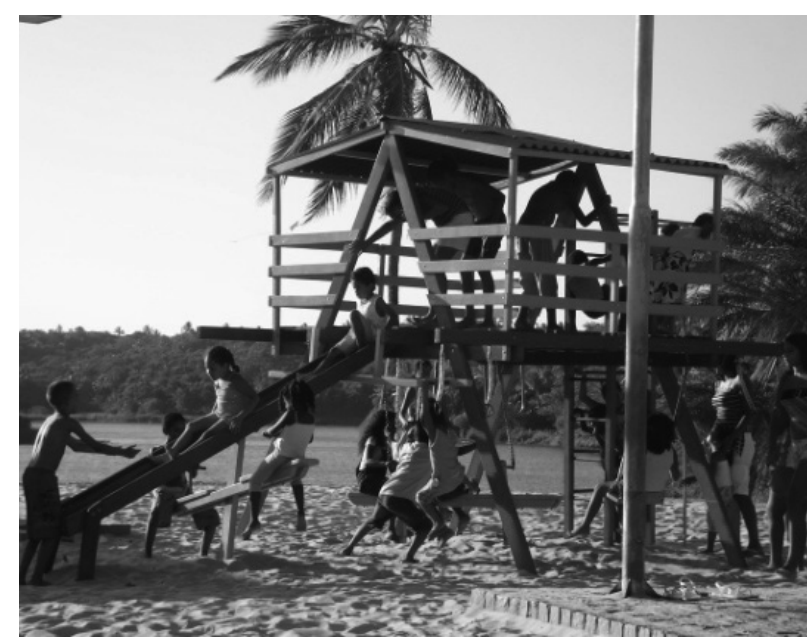

Figura 1. Exemplo de um lugar planejado e um não planejado.

Nos locais planejados, adstritos aos parquinhos públicos, ateve-se à delimitação espacial dos brinquedos públicos destinados às crianças, mesmo nos locais que compreendem praças, áreas florestais e lagoas. Já os locais não planejados, abarcam ruas, canteiros centrais entre avenidas, áreas amplas e livres, praças sem equipamentos infantis. Ademais dessa diferenciação de características, os locais diferem quanto ao contexto social circunjacente e nível socioeconômico dos bairros onde estão situados. Os locais para efetivamente fotografados foram: Parquinho da Praça Nossa Senhora da Luz; Parquinho do Dique do Tororó; Parquinho do Parque Metropolitano de Pituaçú; Parquinho do Largo do Tanque; Parquinho da Praça Luiz Tarquínio;

Já os locais não planejados para crianças abarcaram 10 áreas que possuíam como característica a não presença de equipamentos infantis, pelo contrário, em geral, representam o ambiente inóspito de uma grande cidade. São locais que chamam atenção por serem considerados inadequados para crianças devido às condições de riscos que apresentam ao estarem próximos de grandes avenidas de fluxo intenso de automóveis, canais e rios abertos, entre outras condições. Os efetivamente fotografados foram: Canteiro Central da Avenida Lucaia; Canteiro Central da Avenida Vasco da Gama; Canteiro Central da Avenida Ogunjá; Canteiro Central da Avenida Garibaldi; Passeios de Ruas diversos; Rua no bairro da Federação; Rua no bairro de Brotas; Rua no bairro da Boca do Rio; Rua do fim de linha do Engenho Velho de Brotas; Área adjacente ao Shopping Aeroclube.

\section{Situação}

Os dados foram coletados em vários locais espalhados pela cidade de Salvador (BA), que foram categorizados inspirados na divisão proposta por Rasmussen (2004) em: locais para (planejados pelos adultos) e locais não para crianças (não planejados). A Figura 1 ilustra com fotos os dois tipos de locais:

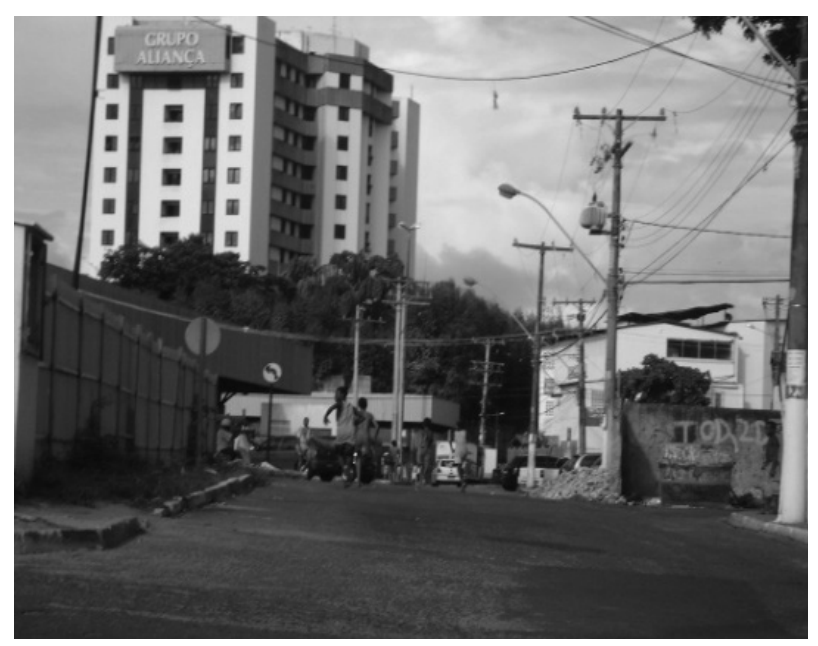

\section{Procedimento}

Os dados foram levantados através de registros fotográficos de eventos de brincadeira nos locais planejados para brincadeiras, e, em seguida, em locais livres onde fossem encontradas crianças brincando, que posteriormente consistiram nos locais não planejados.

Primeiramente se fez um levantamento sobre locais e horários onde poderia haver crianças brincando. Após terem sido visitados diversos locais em dias e horários diferentes, constatou-se que os horários da tarde $(15 \mathrm{~h} 00 \mathrm{~min}$ as $17 \mathrm{~h} 00 \mathrm{~min}$ ) apresentavam maior frequência de crianças em situação de brincadeira nos contextos estudados, levando ao grupo de pesquisadoras a adotarem esse horário como padrão para a realização da coleta, que foi desenvolvida entre os meses de dezembro/2007 a maio/2008.

A dinâmica da coleta consistia em percorrer a cidade de carro e parar (quando isso era possível) onde se avistavam crianças brincando e tirar fotos dos eventos de brincadeira. Os registros fotográficos foram realizados de forma a obedecer à distância necessária para que não houvesse a identificação das crianças e das pessoas presentes, mas que, no entanto, permitisse claramente a identificação das formas de ocupação dos espaços urbanos, tipos de brincadeiras registradas, quantidade de crianças, gênero das crianças entre outros fatores. Eram feitos vários registros fotográficos, porém apenas um era utilizado na análise dos dados, exatamente aquele que permitisse melhor visualização das variáveis envolvidas. Para tal, era feita votação entre membros do grupo de pesquisa e eventuais colaboradores que atuavam como juízes neutros. 
Cotrim, G. S. \& Bichara, I. D. (2013). O Brincar no Ambiente Urbano: Limites e Possibilidades em Ruas e Parquinhos de uma Metrópole.

\section{Análise dos Dados}

Devido à riqueza dos dados, optou-se pela utilização do método quantitativo e qualitativo de forma combinada. Os eventos de brincadeira registrados foram agrupados de acordo com o tipo de ação predominante. Para tal se utilizou as mesmas categorias empregadas por Morais e Otta (2003), a partir de uma combinação dos critérios de Parker (1984) e Piaget (1945/1971):

- Brincadeiras de exercício físico: são brincadeiras com movimento, de cunho predominantemente motor, em que as crianças exercitam comportamentos diversos, com certo vigor físico;

- Brincadeiras de contingência social: envolvem revezamento social, são aparentemente atreladas ao prazer associado à capacidade de produzir respostas contingentes, assim como responder contingentemente aos outros;

- Brincadeiras de construção: envolvem uso e combinações de materiais que são modificados para criar um produto novo;

- Brincadeiras turbulentas: envolvem duas categorias: as agonísticas, relativas à luta e perseguição e fuga; e testes de limite físico e social, que envolvem desafio físico ou provocação e zombaria;

- Brincadeiras simbólicas: são as de faz de conta, nelas as crianças criam personagens, atribuem e representam papéis, tratam objetos como se fossem outros, atribuindo-lhes propriedades diferentes das comuns;

- Brincadeiras com regras: são normalmente os jogos ou as brincadeiras que envolvem regras, com ritualização de papeis, com representação de cenas predeterminadas, sendo, em geral, competitivos. Entretanto existem formas em que podem ser brincados por apenas uma criança que, sozinha, atende às regras de sua brincadeira.

Assim, os dados sobre os eventos de brincadeira, passíveis de quantificação, foram dispostos em uma planilha do Microsoft Excel, onde puderam ser comparados entre si. Qualitativamente puderam ser avaliados os tipos de brincadeiras registradas, as características dos locais de ocorrência, a presença e participação de adultos, usos e adaptações dos espaços conforme as brincadeiras, tipos de brincadeiras encontradas em cada local, além de gênero entre outros elementos.

\section{Questões Éticas}

O presente projeto foi aprovado pelo Comitê de Ética da Faculdade de Filosofia e Ciências Humanas da Universidade Federal da Bahia (UFBA) com isenção de consentimento informado baseado na Resolução $\mathrm{n}^{\circ} 016$ do Conselho Federal de Psicologia (CFP), de 20 de dezembro de 2000 , que prevê, no artigo $6^{\circ}$, que o psicólogo pesquisador poderá estar desobrigado do consentimento informado nas situações em que:

I - envolvem observações naturalísticas em ambientes públicos . . . em que não há risco de violar a privacidade dos indivíduos envolvidos nem de causar a eles ou aos grupos e comunidades aos quais pertencem, qualquer tipo de constrangimento.

\section{Resultados e Discussão}

A unidade de análise utilizada foi a imagem fotográfica que melhor representasse cada evento de brincadeira encontrado, assim, a foto escolhida, dentre várias batidas da mesma posição, consistiu na que melhor abarcava a brincadeira, a quantidade de brincantes, as características do local, gênero das crianças, entre outros fatores.

Os eventos foram classificados a partir do tipo de brincadeira exercida, sendo considerados eventos diferentes os que envolviam brinquedos diferentes, e, portanto, situações diferentes, assim como, os que envolviam brincantes ou grupos de brincadeira distintos.

Ao todo, foram computados 111 eventos de brincadeira, sendo 91 eventos ocorridos em parquinhos públicos e 20 eventos obtidos em espaços não planejados para crianças. A disparidade entre os números de eventos de brincadeira entre os 2 tipos de locais se deve às diferenças em condições de realização dos registros e condições gerais de permanência das crianças. Enquanto em praças e parques os pesquisadores permaneciam por mais tempo registrando várias ocorrências, em vários grupos de crianças presentes no local no momento dos registros, nos locais não para os pesquisadores registravam o que era possível. Por várias vezes esse registro se deu a partir de um carro em movimento.

\section{As Brincadeiras}

Primeiramente procedeu-se a alocação das brincadeiras identificadas nas fotos nas categorias propostas por Morais e Otta (2003), conforme o caráter predominante da ação. $\mathrm{O}$ critério de ação predominante se dá, segundo as autoras, porque as crianças brincam de forma livre e frequentemente misturam características diversas em brincadeiras criativas e inovadoras o que dificulta a tarefa do pesquisador que necessita de critérios para realizar sua tarefa de transformar o observado, ou seja, brincadeiras novas, às vezes "inventadas" no momento, em dado de pesquisa. Os dados referentes a cada categoria conforme os tipos de local estão dispostos na Tabela 1.

Como pode ser visto, há forte preferência pelo tipo de brincadeira associada ao tipo de local. Enquanto nos locais para as crianças brincam majoritariamente de brincadeiras de exercício físico (subir e descer dos aparelhos, escorregar, pular, entre outras), nos locais não para há prevalência dos jogos de regras (futebol, vôlei, guerra de pipas, entre outros).

Chama a atenção a ausência de ocorrência de eventos de brincadeiras simbólicas que pode estar associada a diversas hipóteses. Uma delas seria o tipo de método utilizado para a pesquisa e a forma com que as brincadeiras simbólicas são caracterizadas. As fotografias não permitem registrar as falas das crianças, nem mesmo o conteúdo simbólico dos eventos, por isso, acredita-se que o tipo de método não é apropriado para o estudo desse objeto. 
Tabela 1

Quantidade de Eventos de Brincadeira Encontrados por Local, Conforme as Categorias de Ação

\begin{tabular}{lcccc}
\hline & \multicolumn{4}{c}{ Frequencia de eventos } \\
\cline { 2 - 5 } \multicolumn{1}{c}{ Categorias } & \multicolumn{2}{c}{ Locais para } & $N$ & Locais não para \\
\cline { 2 - 5 } & $N$ & 81,3 & 1 & 5,0 \\
\hline Exercício físico & 74 & 9,9 & 1 & 5,0 \\
Contingência social & 9 & 0 & 1 & 5,0 \\
Construção & 0 & 3,3 & 0 & 0 \\
Turbulenta & 3 & 0 & 0 & 0 \\
Simbólica & 0 & 5,5 & 17 & 85,0 \\
Jogos de regras & 5 & 100 & 20 & 100 \\
\hline Total & 91 & &
\end{tabular}

Esse dado, portanto, necessita ser melhor examinado em trabalhos futuros.

Os demais dados, entretanto, levam a forte associação das brincadeiras encontradas nos locais para com os aparelhos de parquinhos, o que demonstra a atratividade que esses equipamentos exercem sobre os brincantes (Bichara, Fiaes, Marques, Brito, \& Seixas, 2006). Esses achados corroboram com outros estudos que constatam que o tipo do espaço, sua conformação e os equipamentos disponíveis, estimulam a realização de brincadeiras com muita movimentação e altos graus de repetição (Johnson, Cristie, \& Yawkey, 1999). As brincadeiras mais encontradas nos parquinhos foram: subir e escorregar, balançar-se, pular e pendurar-se, apresentando todas elas, mais de 5 eventos ocorridos.

Embora os equipamentos dos parques exerçam grande atratividade nas crianças, concentrando a maioria dos episódios de brincadeiras, houve ocorrências de brincadeiras distanciadas destes brinquedos, principalmente de brincadeiras com regras como a de futebol no Parque Pituaçú, iô iô no Dique do Tororó e jogo de gude na Praça Luiz Tarquínio. Nos dois primeiros locais todos os equipamentos disponíveis se encontravam repletos de crianças o que pode ter influenciado na opção por outra brincadeira. Já o evento de jogo de gude coincidiu com a época em que essa brincadeira, de ocorrência sazonal (Carvalho \& Pontes, 2003), pôde ser visto em outros lugares.

Já nos locais não planejados, as brincadeiras encontradas foram: pipa, futebol, vôlei, areia e de imitação. Em sua maioria brincadeiras com regras que exigem muito mais requisitos para que aconteçam, pois são brincadeiras mais complexas. Aqui a atratividade parece ser o próprio espaço, pois crianças e jovens se dirigem a eles para realizar um determinado tipo de atividade.

Os locais não planejados se restringem basicamente aos canteiros centrais entre avenidas à beira dos rios, quando estes se encontram a céu aberto, ou por cima dos rios, se estes, são subterrâneos, portanto, próximos de canais e de avenidas de grande fluxo e às ruas que possuem movimentação de automóveis, ou algumas ruas no interior dos bair- ros com menor movimentação de veículos e transeuntes. Todos apresentando algum grau de risco, tanto no próprio espaço onde ocorria a brincadeira, como no entorno.

A esse respeito, durante a coleta de dados foi possível registrar alguns eventos bastante ilustrativos desses riscos, como crianças sentadas no meio fio de corredores de ônibus, brincadeiras de pipa, que exigem espaços amplos, ocorrendo em espaço limitado por avenidas, lata de linha de carretel no meio dos carros em movimento e a avenida ser invadida por uma criança para pegá-la, entre outros exemplos.

Essa constatação nos remete a outra questão que é a da participação dos adultos nestes contextos e sua participação nos eventos de brincadeiras e interações entre as crianças.

\section{Participação dos Adultos}

Não houve diferença na quantidade total de eventos em que foi registrada a presença de adultos entre os dois tipos de local (65\% e $61 \%$ respectivamente). Apesar desse dado não poder ser absolutizados, pois poderia haver adultos fora do espaço de abrangência dos registros fotográficos, pode-se perceber uma diferença marcante no tipo de papel desempenhado pelos adultos de um tipo de local para outro: cuidador e brincante.

Verificou-se que nos parquinhos (locais para) os adultos não somente acompanhavam as crianças, mas as auxiliavam nas brincadeiras, como empurrá-las no balanço, girá-las no carrossel ou imprimir força para movimentar a gangorra. Tal como foi observado, a atuação dos adultos se dava como sujeitos que proporcionavam a brincadeira à criança, mas não era um brincante propriamente dito. Vale ressaltar que a interferência dos adultos nas brincadeiras acontecia mesmo com a presença de outras crianças nos equipamentos infantis e, em alguns casos, interferindo nas interações entre crianças.

Em contrapartida, nos locais não para todos os adultos estavam participando efetivamente das brincadeiras, principalmente nas tradicionais como empinar Pipa e nos jogos de Bola, compostas por adultos e crianças. A Figura 2 ilustra os dois tipos de participação dos adultos. 


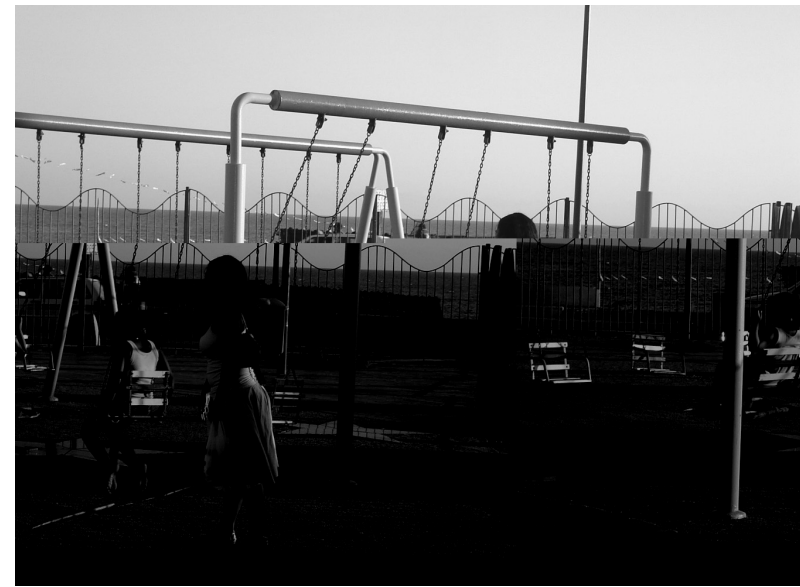

Figura 2. Tipos de participação dos adultos.

Essa distinção de papéis nos leva a refletir sobre quem são esses adultos e crianças que freqüentam um e outro lugar e sobre as formas de ocupação desses espaços, suas localizações e posicionamentos sociais. Aparentemente nos locais planejados as crianças são levadas por pais e/ou babás, enquanto nos locais não planejados por adolescentes e adultos jovens.

Antes de qualquer análise é preciso narrar as peculiaridades geográficas e sociais da cidade de Salvador, com seus morros ocupados no alto pela classe média e nas encostas pela população mais pobre. Esses morros são rodeados por áreas de vales com rios e canais, só recentemente urbanizadas através da construção das chamadas avenidas de vale. Enquanto no alto dos morros e em alguns bairros, localizados em áreas planas da orla ou cidade baixa, existem praças com parquinhos e alguns parques metropolitanos, nas encostas só existem ladeiras e escadarias e nenhum equipamento para crianças. Esta ausência também pode ser observada em bairros pobres da periferia e nas chamadas invasões ${ }^{1}$.

Assim, é possível inferir que o público que freqüenta um e outro lugar é de origem social diferente: nos parques e praças encontramos majoritariamente os moradores dos bairros localizados no alto dos morros ou regiões planas da orla e cidade baixa, enquanto nas avenidas, canteiros, rotatórias etc., moradores das encostas e outras localidades sem equipamentos públicos para crianças.

Enquanto nos locais para, a ocupação e o uso são realizados conforme o planejado, nos locais não para se verifica um processo de apropriação e ressignificação dos mesmos. Chama à atenção também a diferença de participação de meninos e meninas conforme o tipo de local.

1 Invasão é como em Salvador se denomina áreas residenciais afaveladas e/ou ocupadas irregularmente pela população.

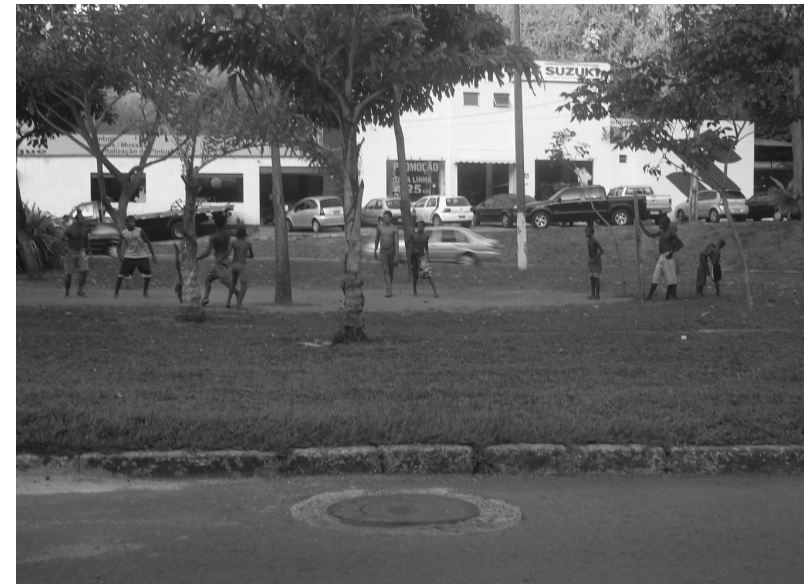

\section{Participação dos Gêneros}

Em relação ao gênero, como pode ser visto na Figura 3 , foram registrados 63 eventos envolvendo grupos exclusivamente de meninos, 53 em grupos de meninas e 4 em grupos mistos. Quando se discrimina esses dados pelo tipo de local constata-se que nos parquinhos não existem diferenças significativas na participação de grupos masculino e feminino (44 e 51 respectivamente), mas pouca presença de grupo misto (2).

Esse achado corrobora com achados anteriores encontrados em Salvador (Fiaes, Marques, Cotrim, \& Bichara, 2010) diferindo no entanto, com dados relativos a outras cidades. Na pesquisa sobre gênero realizada por Karsten (2003), por exemplo, em oito parquinhos públicos em Amsterdam meninas compunham 1/3 do contingente de crianças usuárias desse tipo de local, com uma variação entre 15 a $40 \%$ em relação aos meninos.

Os dados de Salvador chamam a atenção pela aparente contradição existente entre a formação dos grupos segregados e a igualdade no tipo de brincadeira desenvolvida nos locais planejados. A semelhança no tipo de brincadeira pode ser explicada pela não tipificação e estereotipia de gênero dos equipamentos presentes. Ademais, esse dado pode também ser associado à idade predominante (menores de 10 anos) e pelo tipo de participação dos adultos já anteriormente referidos.

Quanto aos locais não planejados, constatamos não ter havido qualquer registro de eventos constituídos somente de meninas, o que comprova que a rua é um espaço de ocupação sexualmente diferenciado. Silva et al. (2006), em uma pesquisa realizada com grupos de brincadeiras de rua na cidade de Belém, encontraram dados que corroboram com a hipótese que a presença de meninos é mais freqüente dos que a de meninas na participação de brincadeiras nas ruas.

Nos espaços não planejados, muito dificilmente era possível visualizar meninas brincando, isso pode se dever ao fato de que os locais aqui registrados são locais em sua maioria amplos, ladeados por avenidas, poucas foram as 
ruas registradas e consideradas mais pacatas e localizadas em locais residenciais. Dessa forma, somente 2 eventos de brincadeiras foram registrados com meninas sendo os dois eventos compostos de crianças de ambos os gêneros.
De acordo com Silva et al. (2006), as meninas mesmo brincando menos na rua, quando brincam, o fazem mais em grupos mistos que em grupos do mesmo gênero, fator este possível de ser relacionado com a pouca disponibilidade de parceiros do mesmo sexo.

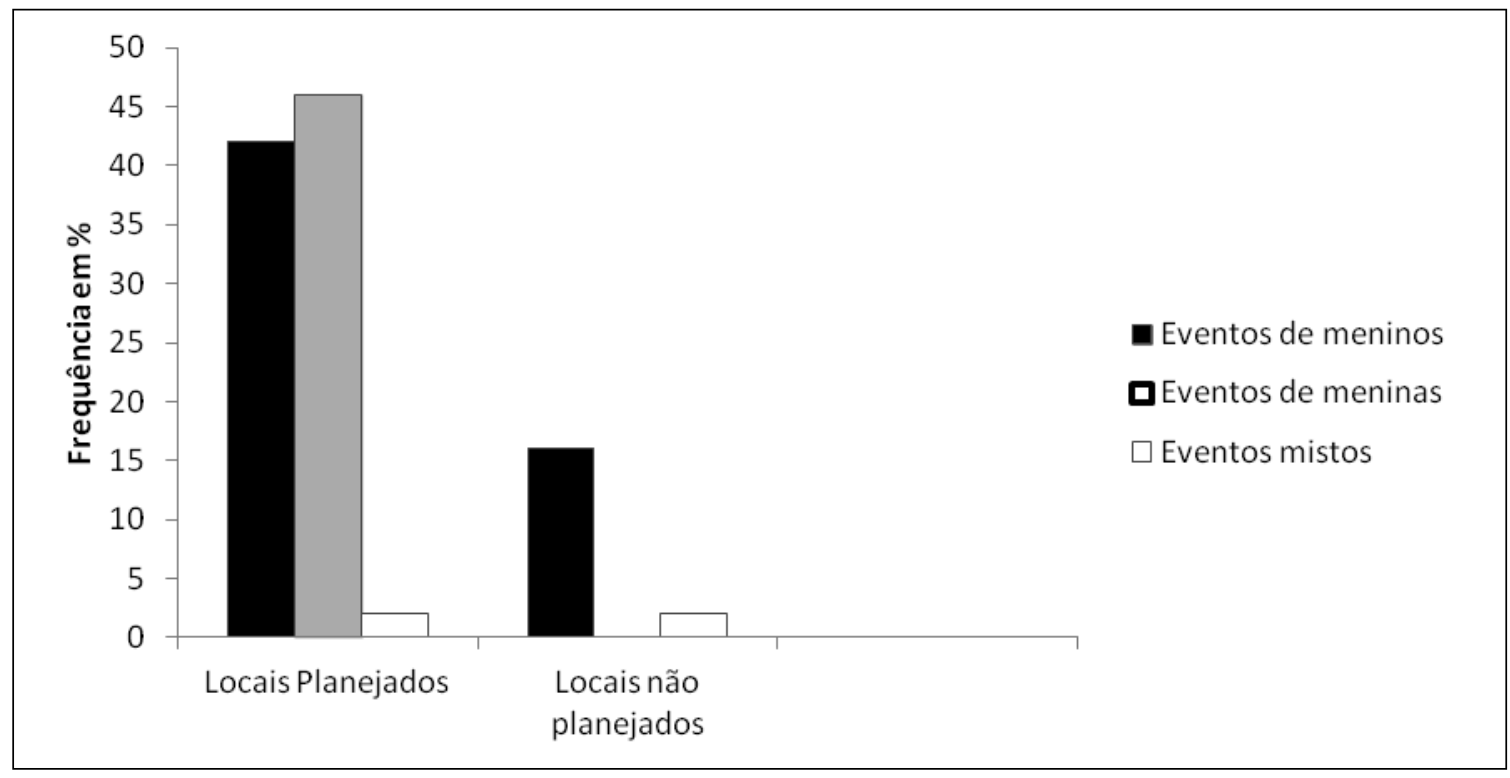

Figura 3. Frequência relativa, em termos de porcentagem, com relação a presença de grupos de meninos, meninas e mistos de acordo com o local.

\section{Considerações Finais}

Segundo Sutton-Smith (2003) no ocidente há uma tendência histórica de domesticação das brincadeiras. Cada vez mais as crianças têm sido alvos de supervisão e controle demasiados por parte dos adultos, que sustentam o argumento de assim o fazerem a título de proteção. De acordo com Mekideche (2004), se o medo dos pais em relação aos seus filhos acelerou a exclusão das crianças de todo espaço público, foi relegado à criança, nos momentos de lazer, o confinamento em locais institucionalizados, sob a guarda de adultos.

Colonna e Brás (2011) se referem a uma imagem que segundo os autores descreve a situação das crianças no contexto das cidades que é a idéia da "insularização", ou seja, as crianças passam cada vez mais tempo em lugares criados para elas, muitas vezes diferenciados por idade, espalhados como ilhas no mapa da cidade. Isso nos leva a grandes reflexões sobre os contextos contemporâneos de desenvolvimento, principalmente nas metrópoles brasileiras.

Os dados aqui descritos apontam para uma diferenciação entre os tipos de brincadeiras encontradas, gênero dos brincantes e forma de participação dos adultos nas brincadeiras de acordo com os tipos de locais públicos investigados (locais planejados e não planejados para crianças). Neste sentido, pôde-se perceber que enquanto nos locais para as brincadeiras encontradas eram predo- minantemente de exercício físico, nos locais não para, a predominância foi das brincadeiras com regras.

Ademais, constatou-se uma diferença marcante no tipo de papel desempenhado pelos adultos de um tipo de local para outro: cuidador e brincante; e na presença dos gêneros em cada local levando a crer que a rua é um espaço de ocupação sexualmente diferenciado.

Estudos como estes tem o objetivo, ao descrever as condições de ocupação e restrições do espaço urbano para as crianças, alertar pais, educadores, responsáveis pelo poder público, planejadores, entre outros, para refletir sobre a cidade como contexto de desenvolvimento, sendo os aspectos relacionados ao brincar apenas a ponta do iceberg.

\section{Referências}

Bartlett, S. (2002). Building better cities with children and youth. Environment and Urbanization, 14, 3.

Bichara, I. D., Fiaes, C. S., Marques, R. L., Brito, T., \& Seixas, A. A. C. (2006). Brincadeiras em contexto urbano: Um estudo em dois logradouros em Salvador (BA). Boletim da Academia Paulista de Psicologia, 26, 39-52.

Carvalho, A. M. A., \& Pontes, F. A. R. (2003). Brincadeira é cultura. In A. M. A. Carvalho, C. M. C. Magalhães, F. A. R. Pontes, \& I. D. Bichara (Eds.), Brincadeira e cultura: Viajando pelo Brasil que brinca: Vol. 1. O Brasil que brinca (pp. 15-30). São Paulo, SP: Casa do Psicólogo.

Christensen, P., \& O'Brien, M. (2003). Children in the City: Home, neighborhood and community. New York: Routledge. 
Cotrim, G. S. \& Bichara, I. D. (2013). O Brincar no Ambiente Urbano: Limites e Possibilidades em Ruas e Parquinhos de uma Metrópole.

Colonna, E., \& Brás, E. J. (2011). Crianças e espaço urbano em Maputo. In V. R. Müller (Ed.), Crianças dos países de língua portuguesa: Histórias, cultura e direitos. (pp. 139-188). Maringá, PR: Editora da Universidade Estadual de Maringá.

Ellis, J. (2004). Researching children's place and space. Journal of Curriculum Theorizing, 20(1), 83-99.

Fiaes, C. S., Marques, R. L., Cotrim, G. S., \& Bichara, I. D. (2010). Gênero e brincadeira em parquinhos públicos de Salvador (BA). Interação em Psicologia, 14(1), 31-41.

Flick, U. (2009). Introdução à pesquisa qualitativa (3. ed.). São Paulo, SP: Artmed.

Göncün, A., Tuermer, U., Jain, J., \& Johnson, D. (1999). Children's play as cultural activity. In A. Göncün (Ed.), Children's engagement in the world, sociocultural perspectives (pp. 148170). New York: Cambridge University Press.

Johnson, J. E., Christie, J. F., \& Yawkey, T. D. (1999). Play and early childhood development ( $2^{\text {nd }} \mathrm{ed}$.). New York: Longman.

Karsten, L. (2003). Children's use of public space: The gendered world of the playground. Childhood (London), 10(4), 457-473.

Karsten, L., \& Vliet, W. (2006). Children in the city: Reclaiming the street. Children, Youth and Environments, 16(1), 151-157.

Kobarg, A. P. R., Kuhnen, A., \& Vieira, M. L. (2008). Importância de caracterizar contextos de pesquisa: Diálogos com a psicologia ambiental. Revista Brasileira Crescimento Desenvolvimento Humano, 18(1), 87-92

Lordelo, E. R. (2002). Contexto e desenvolvimento humano: Quadro conceitual. Apresentação. In E. R. Lordelo, A. M. A. Carvalho, \& S. H. Koller (Eds.), Infância brasileira e contextos de desenvolvimento (pp. 5-18). São Paulo, SP: Casa do Psicólogo.

Matthews, H. (2003). The street as a liminal space: The barbed spaces of childhood. In P. Christensen \& M. O'Brien (Eds.), Children in the city: Home, neighborhood and community (pp. 101-117). New York: Routledge.

Mekideche, T. (2004). Espaços para crianças na cidade de Argel: Um estudo comparativo da apropriação lúdica dos espaços públicos. In E. T. O. Tassara, E. P. Rabinovich, \& M. C. Guedes (Eds.), Psicologia e ambiente (pp. 143-167). São Paulo, SP: Educ.

Meneghini, R., \& Campos-de-Carvalho, M. I. (2003). Arranjo espacial na creche: Espaços para interagir, brincar isoladamente, dirigir-se socialmente e observar o outro. Psicologia: Reflexão e Crítica, 16(2), 367-378.

Morais, M. L. S., \& Otta, E. (2003). Entre a serra e o mar. In A. M. A. Carvalho, C. M. C. Magalhães, F. A. R. Pontes, \& I. D. Bichara, Brincadeira e cultura: Viajando pelo Brasil que brinca: Vol. 1. O Brasil que brinca (pp. 127-157). São Paulo, SP: Casa do Psicólogo.

Parker, S. T. (1984). Playing for keeps: An evolutionary perspective on human games. In P. K. Smith (Ed.), Play in animals and humans (pp. 271-293). Oxford, UK: Basil Blackwell.

Piaget, J. (1971). A formação do símbolo na criança. Rio de Janeiro, RJ: Zahar. (Trabalho original publicado em 1945)

Rasmussen, K. (2004). Places for children - Children's places. Childhood, 11(2), 155-173.

Sager, F., Sperb, T. M., Roazzi, A., \& Martins, F. M. (2003). Avaliação da interação de crianças em pátios de escolas infantis: Uma abordagem da Psicologia Ambiental. Psicologia: Reflexão e Crítica, 16(1), 203-215.

Santos, A. K., \& Bichara, I. D. (2005). Brincadeiras e contextos: Alguns pressupostos para o estudo desta relação. In F. A. R. Pontes, C. M. C. Magalhães, \& W. L. Martin (Eds.), Temas pertinentes à construção da Psicologia Contemporânea (pp. 277-297). Belém, PA: Editora da Universidade Federal do Pará.
Silva, L. I. C., Pontes, F. A. R., da Silva, S. D. B., Magalhães, C. M. C., \& Bichara, I. D. (2006). Diferenças de gênero nos grupos de brincadeiras na rua: A hipótese de aproximação unilateral. Psicologia: Reflexão e Crítica, 19(1), 114-121.

Sutton-Smith, B. (2003). Play as a parody of emotional vulnerability. Play \& Culture Studies, 5, 3-17. 